\title{
Investigation on the potential of poplar bark from short-rotation coppices as bio-based fungicidal additives
}

\author{
Martina Bremer ${ }^{1}$ (D) $\cdot$ Javane Oktaee $^{2} \cdot$ Daniela Einer $^{2} \cdot$ Steffen Fischer ${ }^{1} \cdot$ André Wagenführ $^{2}$
}

Received: 3 July 2020 / Accepted: 20 January 2021 / Published online: 15 March 2021

(C) The Author(s) 2021

\begin{abstract}
Bark on trees protects the plant against environmentally adverse conditions as well as fungi and insect attacks. There are different chemical substances, mostly in the outer bark of trees, which can stop fungi from developing. Bark as a by-product of wood plantations is available in high quantity and can serve as an excellent source for the production of eco-fungicides. In the presented article, bark of various poplar clones from two short-rotation coppices (SRC) in Poland and Germany was examined to determine the chemical composition, the possible extraction of potential fungicides (terpenes, aromatic and phenolic substances), and influence of their extracts on slowing the growth of mold fungi. It was proved that the content of the fungicidal substances depends strongly on the clone type. Two methods of extraction-Soxhlet and batch-were compared to obtain fungicidal extracts. Fungicidal substances were found in extracts gained with both approaches. Triterpenes, fatty acids, aldehydes, and alcohols were primarily the active fungicides in the Soxhlet extracts, whereas phenolic substances act as fungicides in the batch extracts.
\end{abstract}

Keywords poplar $\cdot$ bark $\cdot$ eco-fungicide $\cdot$ extract composition $\cdot$ extractability $\cdot$ fungicidal tests

\section{Introduction}

Wood, as a sustainable natural material, is susceptible to biological degradation by fungi. Wood-degrading fungi decrease the mechanical properties of the wooden products by decomposing the structural components of the cell walls (i.e., cellulose and lignin), where mold fungi can lower the surface quality of the wood-based products by making colored spores and yielding pigments [1]. Therefore, preservation of wood-based products is a crucial step in the manufacturing of wood and plant-based materials to ensure the quality, both mechanically and aesthetically.

Fungicides are a subgroup of pesticides that inhibit the growth of fungi by damaging their cells or preventing their development. Many of the conventional metal-containing pesticides used in wood preservation industries can cause

Martina Bremer

martina.bremer@tu-dresden.de

1 Institute of Plant and Wood Chemistry, TU Dresden, Pienner Str. 19, 01723 Tharandt, Germany

2 Chair of Wood Technology and Fibre Materials Technology, Institute of Natural Materials Technology, Marschner Str. 39, 01307 Dresden, Germany environmental issues, are hazardous to human health, and have disposal problems [2]. These problems and the rise in the demand for eco-friendly materials have motivated more industries and researchers to look for ecological fungicides in nature, especially for indoor applications [3, 4].

An essential aspect of the production of eco-friendly material with the potential of entering the market is resource availability. The raw material sources must be local and abundant. One such resource is by-products of wood plantations, mostly in the form of bark [5]. The presented research aimed to add higher value to hybrid poplars' bark by producing ecofriendly fungicides. Poplar is one of the most common species in plantations worldwide, with a wide variety of hybrids $[5,6]$. Therefore, a thorough examination of the potential fungicidal substances in various hybrids was necessary. Another aspect is the profitability of the extraction and application of the extracts. This requires processes that can be easily implemented using environmentally compatible solvents.

Plants contain many bioactive compounds. Especially secondary metabolites of shikimate pathways such as phenolics, terpenoids, resins, and alkaloids protect against pathogenic fungi [7], bacteria [8] or herbivorous insects [9]. Phenolic compounds are one of the essential bioactive substances in plants [1, $10,11]$. The five main classes of these substances are phenolic acids, flavonoids, stilbenes, lignans, and tannins [12]. In 
addition, saponins, as well as cyanogen glycosides, can also act as fungicides [10]. Often bioactive compounds were separated from buds exudates, bud resins, or leaves. However, a variety of natural bioactive compounds is also deposited in the bark of trees. Many of them could have economic importance when extracted primarily as biopharmaceuticals [13]. Naturally occurring fungicidal substances in plants with high durability are grouped as tannins, flavonoids, lignans, stilbenes [14, 15], terpenes, and terpenoids $[16,17]$. These substances are mostly found in the heartwood and bark of naturally durable plants and do not have a structural function. These substances can be extracted with organic solvents from the plants and, therefore, are called extractives [18]. Researchers have investigated different methods and solvents to extract the fungicidal substances and apply them as a coating or impregnating agent for wood and wooden products $[5,19]$. For the extraction of phytochemicals from bark, several extraction methods (solvents, supercritical fluids, ultrasound, microwave-assistance, among others) are described [20]. Identification of phytochemicals often combines spectroscopic, chromatographic, and calorimetric methods [21].

In the case of poplar, buds and leaves are very rich in phenolic compounds; hence, many studies on poplar are focused on these materials [22-27]. As early as 1970, Pearl \& Darling described the isolation of various glycosides, pyrocatechol and small amounts of an alkaloid by hot water extraction of Populus deltoids bark [28]. Furfural, 5-hydroxymethylfurfural, benzoic acid, salicylic acid, and catechol were found as bulk compounds of Populus tremuloides bark (from Canadian forest) by a combination of steam explosion and extraction with various solvents [29]. Furthermore, sakuranin as a potential fine chemical was found in higher amounts in acetone extract. Zhang et al. separated ten flavonoids from the stem bark of Populus davidiana extracted with methanol [30]. Different phenolic, salicylic, benzoic, and cinnamic acid compounds could be separated by alkaline aqueous extraction of bark from clones of $\mathrm{P} x$ euroamericana (Italy) [31]. The amount of secondary metabolites in extracts can be increased by the thermo-vacuum treatment of wood (Populus nigra L.)[32].

The main scope of the presented work as a part of the Dendromass for Europe project (D4EU) is to provide an insight into the possibility of applying the bark of poplar hybrids as eco-fungicidal additives for wood-based products against surface mold growth. To reach this goal, three focal points were processed. The bark from fast-growing polar hybrids of two different growing sites were collected and at first extracted with Soxhlet method, using solvents of different polarities. Extracts were analyzed with gas chromatography-mass spectrometry (GC-MS) to identify the compounds. The influence of the type of hybrid as well as of the growing site on the extract composition was considered. After that, the separability of the interesting compounds by batch extraction, compared to Soxhlet extraction, was investigated in a larger scale process. Extracts were again characterized by GC-MS. Finally, the extracts were tested for their activity against different mold fungi. The control material in the mold resistance test was fiber molded packaging material produced by the partner in the project (Pulpack Sp. z o.o. Sp. k.) to solve the mold growth problem on their products.

\section{Material and Methods}

\section{Bark extraction}

Trees from different clones (AF2, AF16, AF18, Hybrid 275 (H275), Oudenberg (OB), Vesten, and Max1) and locations (Poland - Plantations of GreenWood (GW) Resources Europe, Ltd., Wojciechowo, 54 $4^{\circ}$ N, $20^{\circ} 8^{\prime}$ E; Germany Agricultural and forestry enterprise Frank Uhlemann,

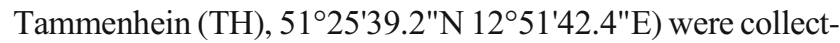
ed. Both cultivation areas belong to the same climatic zone and show a similar annual temperature and rainfall profile (Fig. 1). It should be noted that both regions were affected similarly by the very dry years of 2018 .

The felling was in spring, and all trees were 4 to 7 years old. These trees were then manually debarked. Bark was dried at $45^{\circ} \mathrm{C}$ and milled using a cross-beater mill with a $4 \mathrm{~mm}$ sieve, and the obtained bark particles were used in all the following investigations. The examined hybrids are summarized in Table 1.

Soxhlet extraction of poplar bark using an extraction sequence with GC pure solvents of different polarities (hexane, toluene, ethanol) was carried out to identify the bioactive compounds. To prepare the samples for the GC-MS analysis, $2 \mathrm{~g}$ of milled bark was filled in a cellulose thimble, which was placed in a $30 \mathrm{ml}$ Soxhlet apparatus. The extraction process was then performed with $60 \mathrm{ml}$ of solvent for $6 \mathrm{~h}$. The resulting solvent was removed using a rotary evaporator. After that, the solid extract was solved in $2 \mathrm{ml}$ of GC pure solvent, and the solution was analyzed using GC-MS. This method is referred to in this paper as analytical extraction.

For investigations of extractability (preparative extraction), a Soxhlet extractor of $500 \mathrm{ml}$ was used. Between 40 and $100 \mathrm{~g}$ of milled bark were extracted with $1200 \mathrm{ml}$ solvent (ethanol or acetone) for $6 \mathrm{~h}$. Then $5 \mathrm{ml}$ of the extract were removed for GC-MS examinations. For batch extractions, 40-100 g milled bark was stirred at room temperature and $50{ }^{\circ} \mathrm{C}$ in 500 or $1000 \mathrm{ml}$ solvent (ethanol or acetone) for $1 \mathrm{~h}$. The extract solution was separated by filtration using a glass filter with a porosity of $100 \mu \mathrm{m}$. The solvents of the extract solutions of both methods were removed by rotary evaporation. The solid extracts obtained were used for testing the fungicidal activity. In all of the performed extractions in this research, a pretreatment with washing with water with Soxhlet (2 times, 1 h) or batch (room temperature, 2 times, $1 \mathrm{~h}$ ) was carried out to 


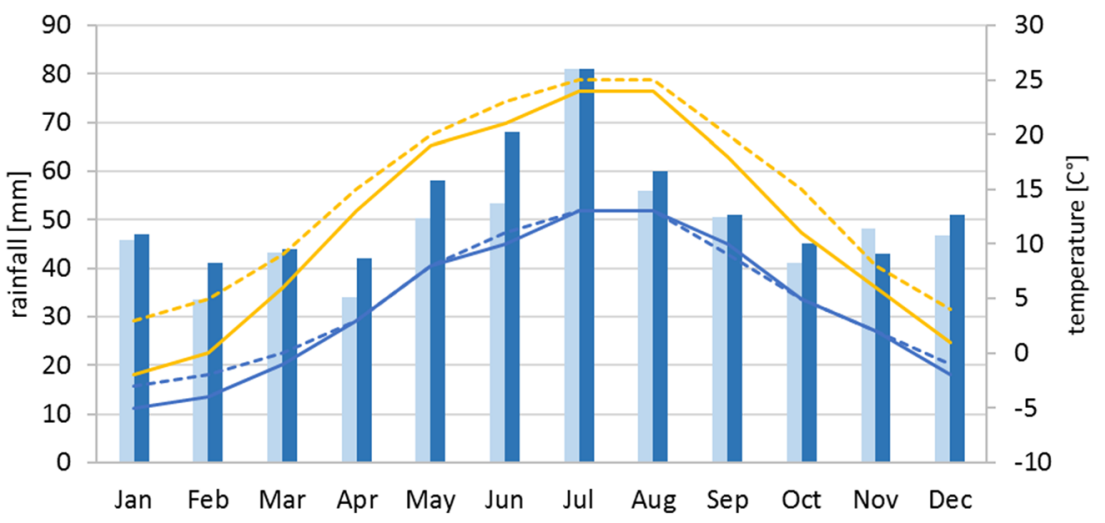

Fig. 1 Climate data for the two growing places of examined poplar hybrids (sources Tammenhain: National Centers for Environmental Information, Orneta: meteoblue); bars: dark blue - rainfall Orneta, light blue - rainfall Tammenhein; lines: yellow dotted - max. temperature

Tammenhein, yellow continuous - max. temperature Orneta, blue dotted - min. temperature Tammenhein, blue continuous - min. temperature Orneta

wash out the reduced sugars before the main extraction with the mentioned solvents.

The GC-MS analysis was carried out with GC 7890B (Agilent) coupled with MSD 5977 (SIM). The test conditions were: column DB-1 from J\&W Scientific ( $30 \mathrm{~m} * 0.25 \mathrm{~mm}$, $0.25 \mu \mathrm{m}$ film thickness), constant helium flow rate of $1 \mathrm{ml}$ $\min ^{-1}$, oven program: from $80^{\circ} \mathrm{C}$ to $300{ }^{\circ} \mathrm{C}$ with $5 \mathrm{~K}$ per min, hold time $10 \mathrm{~min}$, injection temperature $250^{\circ} \mathrm{C}$ and split mode was splitless or 15:1. All measurements were done in the scan mode of the MS. A typical mass scan range from 35 to $500 \mathrm{~m} /$ $\mathrm{z}$ and ionization voltage from $70 \mathrm{eV}$ was used.

The error ranges of extract contents given in Figs. 1-3 are standard deviations for the gravimetrically determined extract amounts after the extraction. These were determined in a separate work [33] for this extraction method using different materials with various extract amounts (2.9 to $11.7 \%$ ); for this purpose, ten extractions were carried out each time. A standard deviation of a maximum $0.7 \%$ was found.

The reproducibility of the preparative extraction was investigated on selected clones (Max1, AF18 GW) by parallel

Table 1 Examined hybris of SRC in Poland (Greenwood, Orneta) and Germany (Agricultural and forestry enterprise Frank Uhlemann, Tammenhein)

\begin{tabular}{lll}
\hline Hybrid & Growing place & Age [years] \\
\hline AF2 & Greenwood Orneta (Poland) & 7 \\
& Tammenhein (Germany) & 4 \\
AF16 & Greenwood Orneta (Poland) & 5 \\
AF18 & Greenwood Orneta (Poland) & 5 \\
Hybrid 275 (H275) & Greenwood Orneta (Poland) & 6 \\
Oudenberg (OB) & Greenwood Orneta & 6 \\
Vesten & Greenwood Orneta (Poland) & 6 \\
Max1 & Tammenhein (Germany) & 5 \\
\hline
\end{tabular}

extraction of three samples. All extracts were estimated quantitatively and analyzed by means of GC-MS. The standard deviation for quantitave analysis was $0.07 \%$. The standard deviation for the peak areas of single substances depends on substance class. The lowest relative errors were found for the phenolic compounds and terpenoids $(<5 \%)$. The largest errors occurred with the fatty acids and fatty aldehydes (up to $10 \%$ ), whereby the relative error concerning the class of fat-based bioactive substances is only approximately $5 \%$.

The identification of the components in the extract was assigned by comparison of their retention indices and mass spectra fragmentation pattern with NIST library 2014. A semiquantitative estimation of the substances, based on the comparison of peak areas, was realized. Only phytochemicals described in literature and sugars were chosen for discussion of the results. All other compounds are summarized as "others" (e.g., higher alkanes, monoterpenes, or not identified compounds). The phytochemicals were classified according to Blomhoff [12]. The amounts of phytochemicals resulting from the peak areas of GC-chromatograms were correlated with the samples' extract amounts.

Various extracts obtained with the mentioned methods and solvents were tested related to slowing the mold fungi growth on the surface of fiber molded packaging materials. The packaging material was made as flat sheets of molded fiber material with a combination of Miscanthus $30 \%$ by weight and corrugated board $70 \%$ by weight (Rapid-Köthen Blattbildungsanlage RK-3A) and then dried at 95 to $100{ }^{\circ} \mathrm{C}$. The two additives used in making the sheets were a cationic sizing agent (PERGLUTIN K2) and a wet strength agent (GILUTON WS 12) in $8 \%$ and $5 \%$. Both chemicals were purchased from Kurita Europe $\mathrm{GmbH}$. The weight of the final sheet was approximately $10 \mathrm{~g}$ per standard sheet. The production of these sheets was based on the information provided by the partners of the project Pulpack (Pulpack Sp. z o.o. Sp. k.). Because these sheets are very homogenous in their structure 
and properties, they serve as a suitable test material for the fungicidal properties of the extracts.

For testing the anti-fungicidal properties of the extracted materials, solid extracts were solved or dispersed in $70 \%$ ethanol with the help of an ultra-sonic bath to reach a concentration of $0.05 \mathrm{~g} \mathrm{ml}^{-1}$. Then sheets were cut (samples of $4 \mathrm{x}$ $4 \mathrm{~cm}$ with $0.5 \mathrm{~g}$ weight) and soaked in the extracts for a few seconds, and were left to dry at room temperature. With this preparation method, a layer of the extract was coating the surface of the sheets.

Five different mold fungi (Aspergillus niger, Paecetomyces variotii, Chateomium globosum, Trichoderma virens, Penicillum pinophillum) were used in the tests. A mixture of the spores was prepared with $3 * 10^{5}$ concentration and spread on the surface of Malt-Agar medium Petri dishes. These Petri dishes were then incubated at $27{ }^{\circ} \mathrm{C}$ until mold covered the surface of the medium. Afterward, they were placed on the prepared Petri dishes and were sealed with parafilm. Sealed Petri dishes were incubated for another 4 weeks at $27^{\circ} \mathrm{C}$ and $90 \%$ RH. For the weekly visual observation of the mold growth on the surface of samples, growth was ranked based on the criteria given in Table 2 . This ranking is adopted from a standard method for mold growth on the surfaces of polymer samples [14], which fits the worst-case scenario protocol well that was developed in this investigation.

\section{Results and Discussion}

\section{Potential fungicides in bark extracts}

Sequential extraction with hexane, toluene, and ethanol showed to be the best method for the analytical investigation of extractable substances. In this part, the extracts' amount and composition are always reported as the sum of the three solvents (hexane, toluene, ethanol). The highest content in all cases was obtained in the ethanol fraction, while hexane and toluene extracts had relatively similar values (Fig. 2).

The total amount of extracts and the content of phytochemicals depend on the hybrid, when other variables in the samples (i.e., the age and harvesting time) are identical. In Online Resource 1, the found phytochemicals are listed for all investigated clones. The stated amounts are the peak areas of the single compounds concerning the peak area of all peaks. The highest extract amounts were found for clones AF18, Hybrid 275, Vesten, and Max1. The composition of extracts depends on the hybrid and site. Exept clones AF18, Vesten, and Max1, phytochemicals' content within the extracts is more than $40 \%$. Clones with the highest extract amounts also show the highest proportions of phenolic phytochemicals. However, the substances within these classes differ between the clones. Catechol and salicylic alcohol are the dominating phenolic phytochemicals in extracts of clones AF2, AF16, AF18, and Vesten of Poland. These compounds have already been described in the literature as the main components of poplar bark extracts [29]. Extracts of clones from Germany (AF2, Max $1 \mathrm{TH}$ ) and clone H275 (GW, Poland) contain fewer amounts of these compounds. Small proportions of phenolic acids referred to by Tyskiewicz et al. [24] could be detected in all clones. Noticeable amounts of the vanillic acid $(6.3 \%)$, known as a fungicide [34], were observed in the toluene extract of Max1. Another known fungicide, salicylic acid $[35,36]$, is often present but mostly in small amounts. The highest content $(3.6 \%)$ was observed in the toluene extract of clone H275. Kis et al. [22] described a moderate activity against fungi of phenolic acids for several poplar buds extracts.

Salicin was the only glycoside found. Also, Pearl \& Darling [28] obtained Salicin beside Salicortin as the main component of hot water extracts of poplar bark. Salicin occurs in noticeable quantities (6-12\%), particularly in the ethanol extracts of clones grown at the German location. In the extracts of clone H275 2-(phenylmethoxy)-phenol was the primary substance (>20\% in toluene and ethanol extracts), which is not reported by any other author. The structure of this compound (Fig. 3) suggests that it is a degradation product of flavonoids or condensed tannins, which were not found in any extract. This assumption is supported by the mass spectrum, which has fragments with mass numbers higher than 200. Various authors reported flavonoids, especially sakuranin, in acetone and methanol extracts from poplar bark [29, 30].

The terpene content is, in general, lower than $10 \%$. The proportion of terpenes is also strongly dependent on the hybrid. Bioactive triterpenes could be detected in somewhat
Table 2 Ranking criteria for mold fungi growth

\begin{tabular}{ll}
\hline $\begin{array}{l}\text { Rank } \\
\text { (Intensity of mold growth) }\end{array}$ & Evaluation criterion \\
\hline $\mathbf{0}$ & No growth apparent under the microscope \\
$\mathbf{1}$ & No growth visible with the naked eye, but clearly visible under the microscope \\
$\mathbf{2}$ & Growth visible with the naked eye, covered up to $25 \%$ of the sample surface \\
$\mathbf{3}$ & Growth visible with the naked eye, covering up to $50 \%$ of the sample surface \\
$\mathbf{4}$ & Considerable growth, covering more than $50 \%$ of the sample surface \\
$\mathbf{5}$ & Intensive growth, covering the entire sample surface \\
\hline
\end{tabular}


Fig. 2 Extract amount and amount of phytochemicals of examined poplar clones in analytical extraction $(\mathrm{GW}$ Greenwood Poland, TH Tammenhein - Germany)
25,00

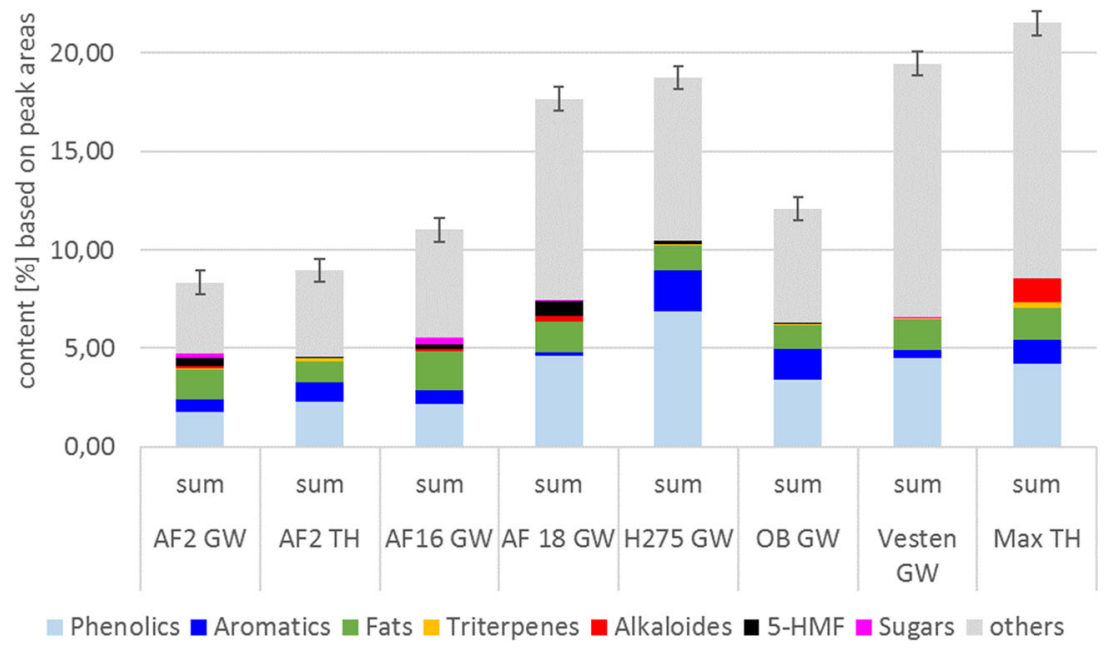

larger quantities, especially in the extracts of the clones harvested in Germany. Devappa et al. [29] described the stigmast-4-en-3-one, found at Max1, as a bioactive steroid in dichloromethane extracts. The aromatic substance class's main components are 2,3-dihydrobenzofuran and benzoic acid, which could be observed in all clones. Benzofuran derivatives usually come from flavonoids, which are potential fungicides [36]. In addition, benzyl alcohol was observed in extracts of AF2 (GW, Poland). A very small amount of ethyl-4ethoxy benzoate and cinnamic acid were detected in clone Max1. Cinnamic acid is found in extracts of polar buds [22]. Another class of bioactive compounds is fatty acids, aldehydes, and alcohols, which were identified in all clones. In most clones, the amounts of fatty acids and fatty aldehydes are similar, approximately $10-15 \%$. Fatty alcohols are the main substances, with 25-40\%. The main components of the fatty compounds are palmitic acid, stearyl aldehyde, and oleyl alcohol. Especially fatty acids such as linolenic acid, linoleic

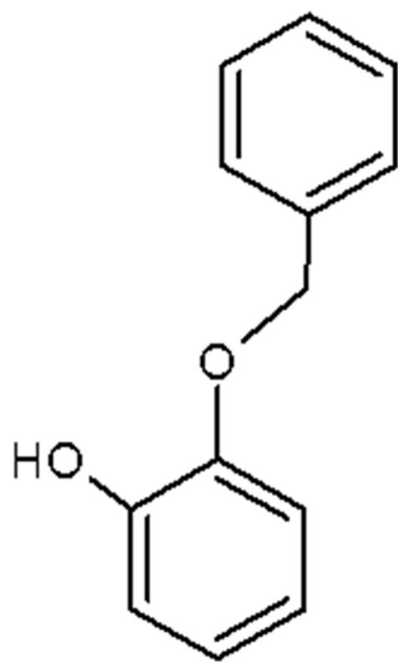

Fig. 3 Structure of 2-(phenylmethoxy)-phenol acid, and olic acid can significantly reduce fungi' biomass production [37]. Furthermore, 5-hydroxymethylfurfural (5HMF) was detected in all ethanol extracts. This degradation product of sugars is known for antimicrobial activity [38]

In addition, the 5-HMF beta-D-glycopyranose was found in different contents. Ethanol extract of clone Vesten contains the highest amount $(9.8 \%)$. This can be a problem for the fungicide activity of extracts. One alkalide (2,6-dihydroxypyridin) was identified only in AF clones from Poland and Max1 from Germany, with the latter having the highest content.

Comparing the AF2 clone from different growing sites showed slight differences in the content of hexane and ethanol extracts. However, the total amount of the extracts were similar. The composition of phytochemicals is also different. While Poland's samples contained aromatic compounds (primarily benzyl alcohol), a higher content of phenolic compounds was observed in German samples. This is mainly caused by larger amounts of salicin, a typical phenolic glycoside in plants of the Salicaceae family (willow, polar) [24]. Samples from both regions contain only small amounts of triterpenes. Stigmast-4-en-3-one was only found in the German samples in hexane extract. The total content of phytochemicals from fats are similar, but composition varies. While the fatty alcohols, in particular, stearyl alcohol, predominate in Poland's samples, high proportions of fatty aldehydes (essentially stearyl aldehyde) were also found in the German samples. Palmitic acid, as well as oleyl acid, were found in both samples in small proportions. Because both locations have a very similar climate, the differences are due to age and/or different soil conditions.

\section{The extractability of potential fungicides}

To produces extracts that can be applied as fungicides, simple extraction methods are of interest. Thus, Soxhlet extraction 
Fig. 4 Extract amounts and amount of phytochemicals of AF18 using different extraction methods (W-water, H-hexane, Ttoluene, E-ethanol, A-acetone)

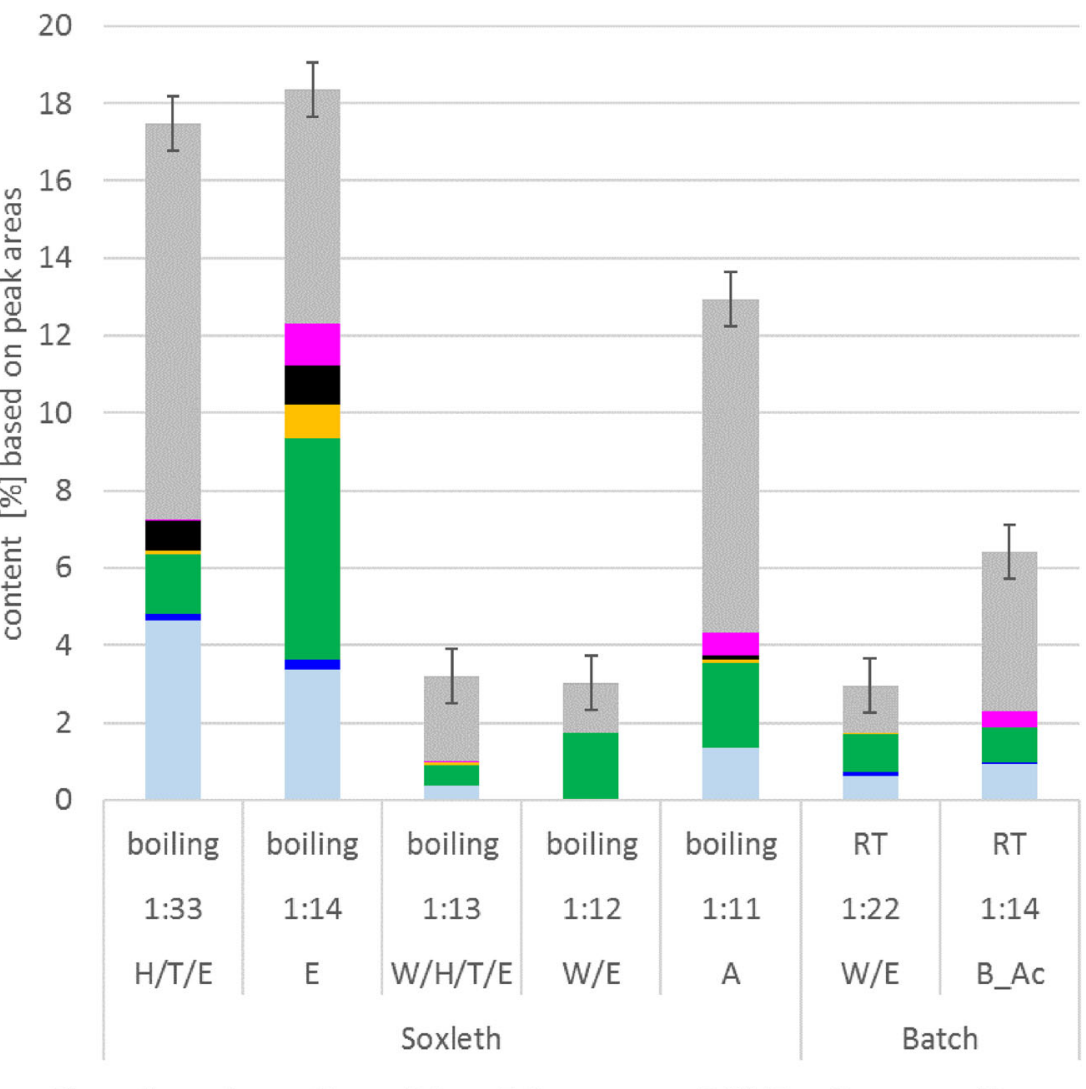

Phenolics and a batch process were compared. Figure 4 shows the extraction method's influence on the extracted content and the extract composition, using clone AF18 as an example.

As a reference, the amount of analytical extraction is shown in the first bar $(\mathrm{H} / \mathrm{T} / \mathrm{E})$. It was observed that the same extract content as seen in the analytical extraction is achieved with a six-hour preparative Soxhlet ethanol extraction, despite the significantly lower liquor ratio. The extract of the preparative Soxhlet extractions is composed differently than the analytical extract. Without pre-extraction with water, the proportion of sugars and fats/waxes is dominant. In addition, only slight amounts of aromatic and phenolic compounds were obtained. After a pre-extraction with water, however, a higher proportion of aromatic and phenolic compounds and terpenoids was observed. The sugars are mostly removed, and the content of fats and waxes increases sharply. Concerning the phytochemicals, it has been shown that the preparative Soxhlet extraction (E) produces more fatty aldehydes (approx. $20 \%$ ) than fatty acids and fatty alcohols. Furthermore, 2,3-dihydrobenzofuran was identified in the preparative extract, which could not be detected in the analytical extraction. This speaks for the formation during the extraction. Among the phenolic compounds, catechol and salicyl alcohol predominate in both extracts, along with small amounts of hydroxybenzoic acids and hydroxycinnamic acids. Overall, however, fewer phenolic compounds are dissolved in the preparative Soxhlet extraction with ethanol.
However, it was shown that this extract is not stable and starts to mold when stored for a long time. The main reason for this should be the low-molecular sugars' presence (polysaccharide building blocks and storage substances). Therefore, water extraction was carried out prior to the main extraction. This leads to a notable reduction in the amount of extracts in the organic solvents (Fig. 4). Only 3/4 of the extract amount of the analytical extraction without water $(\mathrm{H} / \mathrm{T} / \mathrm{E})$ was obtained after water pre-extraction (W/H/T/E).

Primary extraction with the water removed the sugars but also resulted in a reduction in the proportion of aromatic and phenolic compounds and triterpenes (W/H/T/E, W/E). Comparison of analytical (W/H/T/E) and preparative extraction (Soxhlet W/E) show high amounts of fatty alcohols in preparative extract (approx. $50 \%$ ); in contrast to the analytical extract, the fatty acids (mainly palmitic acid) are dominant (>55\%). Phenolic and aromatic compounds, as well as triterpenes, are entirely missing in the preparative extracts.

The batch extractions were carried out with a water preextraction as well. As presented in Fig. 4, the same amount of extract as obtained with preparative Soxhlet extraction $(\mathrm{W} / \mathrm{E})$ was gained with batch extraction after one hour at room temperature. The relatively higher proportion of aromatic/ phenolic compounds and terpenes is remarkable and should be caused by the lower process temperature. The main components are catechol, salicylic alcohol, and small amounts of 
benzaldehyde. By batch extraction, comparable amounts of palmitic acid and linolenic acid were observed. Only small proportions of fatty alcohols and fatty aldehydes were found. The dominant triterpene is stigmast-4-en-3-one. The second step of batch extraction results in a very low yield and contained mostly fats/waxes. It was also found that the batch extraction at a moderately elevated temperature $\left(50{ }^{\circ} \mathrm{C}\right)$ significantly increases the proportion of phenolic compounds.

To avoid a pre-extraction with water and increase the proportion of fungicidal substances in the extract, tests for extraction with acetone, which is less polar than ethanol, were carried out. A relatively high amount of extract was obtained with Soxhlet extraction. However, the extract still contains sugars, albeit slightly less than in the ethanol extract without preextraction with water. Catechol and oleyl alcohol are the primary phytochemicals in preparative Soxhlet acetone extract. The batch extraction with acetone results in a generally lower extract amount. The main phytochemicals are palmitic acid and catechol. Acetone extraction also confirms that more fatty acids are obtained through batch extraction. Table 3 lists the extract amounts of all investigated clones for Soxhlet extraction as well as the first run of batch extraction with ethanol after pre-extraction with water. For some clones, the amounts of extracts from Soxhlet extraction were higher than from batch extraction. These are clones with a high content of fatty substances (long-chain alkanes, alkenes, alcohols, aldehydes, and acids). For AF2, AF16, and OB of Poland, the relative content of fatty substances are approximately $60 \%$ or more. Soxhlet extraction takes place at boiling temperature, and therefore more of the long-chain compounds can be extracted. The lower the proportion of these compounds, the more similar the yields in Soxhlet and batch extraction are. If their content is very low, similar to clone H275, the batch extract amount is higher than in Soxhlet extraction.

In Online Resource 2, the found phytochemicals in Soxhlet and batch extracts are listed for all investigated clones. The stated amounts are the peak areas of the single compounds

Table 3 Extract amounts of preparative ethanol extractions

\begin{tabular}{llll}
\hline Site & Clone & \multicolumn{2}{l}{ Extract amount [\%] wt. } \\
\cline { 3 - 4 } & & Soxhlet & Batch \\
\hline \multirow{2}{*}{ Poland } & AF2 & 2.74 & 0.94 \\
& AF16 & 2.74 & 1.78 \\
& AF18 & 3.09 & 3 \\
& H275 & 1.77 & 2.09 \\
& OB & 2.19 & 1.13 \\
& Vesten & 2.53 & 2.96 \\
Germany & AF2 & 1.81 & 1.72 \\
& Max1 & 3.58 & 3.03 \\
\hline
\end{tabular}

concerning the peak area of all peaks. As illustrated in Fig. 5 , the comparison of the extracts from the preparative Soxhlet and batch extractions proves the extraction method's influence on the extract composition. In general, more aromatic and phenolic substances were obtained with batch extraction, as mentioned above. Again, catechol and salicylic alcohol are the main phenolics for most clones. Only salicylic acid was found in batch extracts of AF2 (TH), OB, and Vesten (GW). Phenol in remarkable amounts (approx. $9 \%$ ) was found in Soxhlet extracts of Max 1, which was not detected in analytical extracts. The source of phenol should be catechol and/or salicylic alcohol because they are missing entirely in this extract. In addition, 2-(phenylmethoxy)-phenol was identified in extracts of clones from Poland of approximately 1 to $2 \%$. As expected, clone $\mathrm{H} 275$ is an exception with more than $60 \%$ in the batch extract. In this clone, the phenol was also found in the Soxhlet extract with approximately $9 \%$, which correlates with the high levels of this compound in the analytical extraction.

The highest number of the potential fungicides were found in the batch extract of the clone Hybrid 275, and the analytical extractions showed the highest amount of these substances. However, there are some clones with comparable content of potential fungicides, such as AF16, AF18, and Oudenberg from Poland (batch) and AF2 from Germany (batch).

As shown in Fig. 4, only the batch extracts of clones AF16, H275 from Poland and Max1 from Germany show smaller proportions of aromatic compounds. These are essentially 2,3-dihydroxy benzofuran and benzoic acid. Among the bioactive fat-based compounds, the fatty alcohols in the Soxhlet extracts and the fatty acids in the batch extracts dominate, especially among Poland's clones. Exceptions are the clones H275 and Vesten, in which the fatty alcohol always has a higher proportion. The extracts from the German clones are similar. In addition, fatty aldehydes occur in different proportions in almost all clones. The highest ratio of stearic aldehyde was found for clone AF16 (GW, Poland). In preparative extractions, only triterpenes were found, which are usually in higher amounts in Soxhlet extracts. Mostly stigmast-4-en-3-one was observed in higher amounts in clone AF2 of both sites.

In conclusion, both preparative methods (Soxhlet and batch extraction) result in extracts with phytochemicals. The amount and composition of phytochemicals depend mainly on the clone. Batch extraction usually results in more phenolic phytochemicals. Higher concentrations of known fungicides are present in Soxhlet extracts of AF2, AF16 (stigmast-4-en-3one), and Max1 (phenol). Batch extracts of H275 contain a very high amount of (2-phenyl methoxy)-phenol. Phenolic phytochemicals, especially catechol and salicylic acid, are present in the other batch extracts. 
Fig. 5 Amounts of phytochmicals of preparative extracts depending on clone and growing location on the basis of peak areas in GC-MS

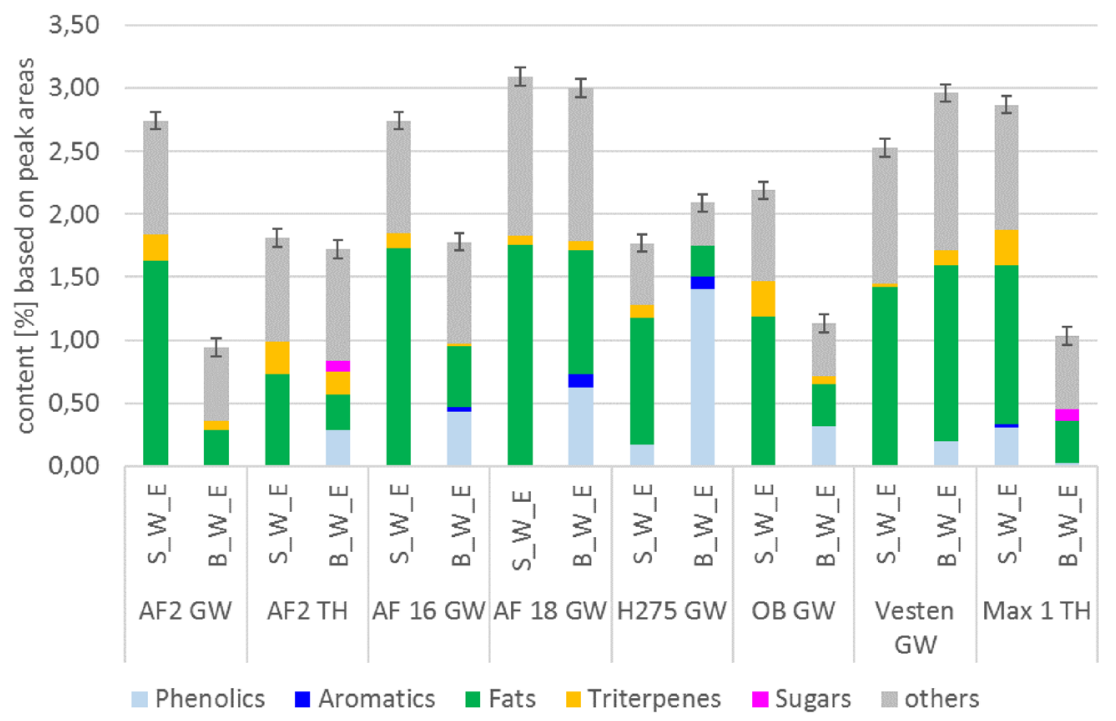

\section{Fungicidal effect of bark extracts}

To determine the effectiveness of the extracts in decelerating the mold growth, tests with five samples and two replications were performed with the test protocol described earlier. The acetone extracts did not work in general due to the contained oligomeric sugars. In Table 4, the fungal growth is listed for the samples with the ethanol extracts compared to the control sheets. Controls were prepared without any additives and treated with $70 \%$ ethanol before inoculation. Notable differences were observed between different extracts. Some of the Soxhlet extracts slowed down the mold fungi growth compared to the control samples. Only the Soxhlet extracts of AF2 (Poland) in double concentration and the two German clones (AF2 and Max1) showed lower mold fungi growing levels from the first observation week. Soxhlet extract of AF16 stops the growth after two weeks but at a little higher level than the mentioned Soxhlet extracts. A small decrease in the mold growth rate was observed for the Soxhlet extract of AF18. These results correlate with the composition of the

Table 4 Ranking of the mold fungi growth on samples coated with ethanol extracts

\begin{tabular}{|c|c|c|c|c|c|c|c|}
\hline \multirow[t]{2}{*}{ Site } & \multirow[t]{2}{*}{ Clone } & \multirow[t]{2}{*}{ Method of extraction } & \multirow[t]{2}{*}{ concentration $[\mathrm{g} / \mathrm{ml}]$} & \multicolumn{4}{|c|}{ Ranking of mold growth } \\
\hline & & & & Week 1 & Week 2 & Week 3 & Week 4 \\
\hline \multirow[t]{12}{*}{ Poland } & AF2 & Soxhlet & 0.1 & 2.2 & 2.25 & 2.5 & 2.5 \\
\hline & \multirow[t]{2}{*}{ AF16 } & Soxhlet & 0.05 & 3 & 3.6 & 3.6 & 3.6 \\
\hline & & Batch & 0.05 & 4 & 4 & 4.2 & 4.4 \\
\hline & \multirow[t]{3}{*}{ AF18 } & Soxhlet & 0.05 & 3 & 3.2 & 3.8 & 4.2 \\
\hline & & Batch & 0.05 & 4.6 & 5 & 5 & 5 \\
\hline & & Batch & 0.1 & 3.2 & 4.2 & 4.2 & 4.6 \\
\hline & \multirow[t]{2}{*}{ Hybrid 275} & Soxhlet & 0.05 & 4 & 4.4 & 4.8 & 4.8 \\
\hline & & Batch & 0.05 & 2.2 & 3.2 & 3.4 & 4 \\
\hline & \multirow[t]{2}{*}{ Oudenberg } & Soxhlet & 0.05 & 4 & 4.2 & 4.6 & 4.6 \\
\hline & & Batch & 0.05 & 3.2 & 4.4 & 4.6 & 4.6 \\
\hline & \multirow[t]{2}{*}{ Vesten } & Soxhlet & 0.05 & 3.6 & 4.2 & 4.6 & 4.6 \\
\hline & & Batch & 0.05 & 4 & 4.8 & 5 & 5 \\
\hline \multirow[t]{3}{*}{ Germany } & \multirow[t]{2}{*}{ AF2 } & Soxhlet & 0.05 & 0.6 & 0.6 & 1.8 & 1.8 \\
\hline & & Batch & 0.05 & 1.2 & 2.6 & 3 & 3 \\
\hline & \multirow[t]{3}{*}{ Max1 } & \multirow[t]{3}{*}{ Soxhlet } & \multirow[t]{3}{*}{0.05} & 1.2 & 2.4 & 2.6 & 2.6 \\
\hline Native control & & & & 2.4 & 4.2 & 4.8 & 5 \\
\hline $70 \%$ ethanol & & & & 3 & 3.4 & 4.4 & 5 \\
\hline
\end{tabular}


extracts mentioned above. Most effective are the extracts containing the highest amounts of stigmast-4-en-3-one (AF2), stearic aldehyde (AF16), and phenol (Max1).

In the batch extracts, only the extracts of clones AF2 (Germany) and Hybrid 275 caused an effective reduction in mold growth. In addition to the triterpene, the batch extract of clone AF2 contains several phenolic compounds in small amounts. This extract also contains approximately $5 \%$ monomeric sugars, and therefore the fungicidal effect is not as notable as in the Soxhlet extract of this clone. The main component of the batch extract of clone H275 is 2-(phenylmethoxy)phenol, which have an activity against mold fungi [39]. However, the fungi growth occurs faster with this extract after the first week than with the Soxhlet extracts of the clone AF2. Therefore, it can be assumed that the effect of stigmast-4-en-3one against molds is more sustainable than that of the phenol. The other batch extracts slow down the growth of fungi only slightly. Hence, catechol and salicylic alcohol have only moderate activity against mold.

\section{Conclusions}

Using a sequential extraction with solvents of different polarity, it was found that the bark of poplar clones from SRC contains different potential fungicides (terpenes, aromatic and phenolic compounds, fatty acids, or aldehydes). The content of these substances depends strongly on the clone and age and only slightly on the growing location. Independent of location, clones Hybrid 275 and Max1 contain the highest amount of potential fungicides of all the investigated clones. Differences between growing locations should be mainly caused by the age of trees or the soil because the climate of the two sites was similar, as explained earlier.

The extractability of the potential fungicides using simple methods is also crucial for producing the extracts as fungicides. For this, the Soxhlet extraction was compared with the batch process. It was observed that the presence of oligomeric sugars requires a pre-extraction with water in both methods. The composition of the extracts obtained is also processdependent in addition to the influences of the clone. The Soxhlet process mainly produces fat-based phytochemicals and triterpenes. The most effective Soxhlet extracts against mold growth are those of high Stigmast-4-en-3one or phenol content. Aromatic and phenolic substances are also contained in the batch extracts, from which 2-(phenylmethoxy)-phenol, catechol, and salicylic alcohol slow the mold growth. The latter, however, requires a higher concentration because of their only moderate activity against mold fungi. Clones with high potential of fungicidal extracts in their bark are AF2, AF16, Max1, and H275. The necessary concentration of extracts for effective activity against molding depends on their comprising substances. In our tests, the concentration of the extracts in batch extraction, which is the more economical method, had to be doubled to show fungicidal effects.

Supplementary Information The online version contains supplementary material available at https://doi.org/10.1007/s12155-021-10253-9.

Funding Open Access funding enabled and organized by Projekt DEAL. This project has received funding from the Bio-Based Industries Joint Undertaking under the European Union's Horizon 2020 research and innovation program under grant agreement No 745874 .

\section{Declarations}

Conflict of interest The authors declare that they have no conflict of interest.

Open Access This article is licensed under a Creative Commons Attribution 4.0 International License, which permits use, sharing, adaptation, distribution and reproduction in any medium or format, as long as you give appropriate credit to the original author(s) and the source, provide a link to the Creative Commons licence, and indicate if changes were made. The images or other third party material in this article are included in the article's Creative Commons licence, unless indicated otherwise in a credit line to the material. If material is not included in the article's Creative Commons licence and your intended use is not permitted by statutory regulation or exceeds the permitted use, you will need to obtain permission directly from the copyright holder. To view a copy of this licence, visit http://creativecommons.org/licenses/by/4.0/.

\section{References}

1. Reinprecht L (2010) Fungicides for Wood Protection - World Viewpoint and Evaluation/Testing in Slovakia. In: Carisse O (ed) Fungicides. IntechOpen. https://oi.org/10.5772/13233

2. González-Laredo RF, Rosales-Castro M, Rocha-Guzmán NE, Gallegos-Infante JA, Moreno-Jiménez MR, Karchesy JJ (2015) Wood preservation using natural products. Madera Bosques 21: 63-76

3. Fernández-Costas C, Palanti S, Charpentier J-P, Sanromán MA, Moldes D (2017) A Sustainable Treatment for Wood Preservation: Enzymatic Grafting of Wood Extractives. ACS Sustain Chem Eng 5:7557-7567

4. Binbuga N, Ruhs C, Hasty JK, Henry WP, Schultz TP (2008) Developing environmentally benign and effective organic wood preservatives by understanding the biocidal and non-biocidal properties of extractives in naturally durable heartwood. Holzforschung 62(1-4):264-269

5. Markoff I (2016) Short Rotation Coppices in Germany. Report of Short Term Scientific Mission (STSM)

6. Dickmann DI, Kuzovkina J (2014) Poplars and Willows of the world, with wmphasis on silviculturally important species. In: Isebrands JG, Richardson J (eds) Poplars and willows: trees for society and the environment. CABI, Wallingford, pp 634-641

7. Rayner AMD, Boddy L (1988) Fungal decomposition of wood. Its biology and ecology. Wiley, Chichester

8. Cowan MM (1999) Plant products as antimicrobial agents. Clin Microbiol Rev 12(4):564-582 
9. Carmona D, Lajeunesse MJ, Johnson MTJ (2011) Plant traits that predict resistance to herbivores. Funct Ecol 25:358-367

10. Oßwald WF, Elstner EF (1987) Investigations on spruce decline in the Bavarian forest. Free Radic Res Commun 3(1-5):185-192

11. Tascioglu C, Yalçin M, Șen S, Akcay C (2013) Antifungal properties of some plant extracts used as wood preservatives. Int Biodeterior Biodegradation 85:23-28

12. Bernhoft A (2010) A brief review on bioactive compounds in plants. In: Bernhoft A (ed) Bioactive compounds in plants - benefits and risks for man and animal. Proceedings from a symposium held at the Norwegian Academy of Science and Letters, Oslo, 1314 Nov 2008, Novus forlag, Oslo

13. Royer M, Houde R, Stevanovic T (2013) Non-wood forest products based on extractives-a new opportunity for Canadian forest industry part 2-softwood forest species. J Food Res 2(5):164-189

14. Dorado J, van Beek TA, Claassen FW, Sierra-Alvarez R (2001) Degradation of lipophilic wood extractive constituents in Pinus sylvestris by the white-rot fungi Bjerkandera $s p$. and Trametes versicolor. Wood Sci Technol 35(1/2):117-125

15. Heldt H-W, Pichulla B (2011) Plant biochemistry, 4th edn. Academic, San Diego

16. Breitmaier E (2006) Terpenes. Wiley-VCH, Weinheim

17. Machado GO, Cookson LJ, Christoforo AL, Polito WL, Silva MR, Calil C Jr, Lahr FAR (2013) Wood preservation based on neem oil: evaluation of fungicidal and termiticidal effectiveness. For Prod $\mathrm{J}$ 63(5/6):202-206

18. Singh T, Singh AP (2012) A review on natural products as wood protectant. Wood Sci Technol 46:851-870

19. DIN (1997) Plastics - Evaluation of the Action of Mikroorganisms vol ISO 846:1997, EN 130 846. Deutsches Institut für Normung e.V.

20. Tiwari P, Kumar B, Kaur M, Kaur G (2011) Phytochemical screening and extraction: a review. Int Pharm Sci 1(1):98-106

21. Vermerris W, Nicholson R (2006) Chapter 4: Isolation and identification of phenolic compounds. In: Vermerris W, Nicholson R (eds) Phenolic compound biochemistry. Springer, Dordrecht, pp 151-196

22. Kis B, Avram S, Pavel IZ, Lombrea A, Buda V, Dehelean CA, Soica C, Yerer MB, Bojin F, Folescu R, Danciu C (2020) Recent advances regarding the phytochemical and therapeutic uses of Populus nigra L. buds. Plants 9:1464-1480

23. Nassima B, Nassima B, Riadh K (2019) Antimicrobial and antibiofilm activities of phenolic compounds extracted from Populus nigra and Populus alba buds (Algeria). Braz J Pharm Sci 55:e18114

24. Tyśiewsicz K, Konkol M, Kowalski R, Rój E, Warmiński K, Krzyżaniak M, Gil Ł, Stolarski MJ (2019) Characterization of bioactive compounds in the biomass of black locust, poplar and willow. Trees 33(5):1235-1263

25. Kuś P, Jerković I, Jakovljević M, Jokić S (2018) Extraction of bioactive phenolics from black poplar (Populus nigra L.) buds by supercritical $\mathrm{CO}_{2}$ and its optimization by response surface methodology. J Pharm Biomed Anal 152:128-136
26. Wu Y-W, Sun S-Q, Zhao J, Li Y, Zhou Q (2008) Rapid discrimination of extracts of Chinese propolis and poplar buds by FT-IR and 2D IR correlation spectroscopy. J Mol Struct 883-884:48-54

27. Popova MP, Bankova VS, Bogdanov S, Tsvetkova I, Naydenski C, Marcazzan GL, Sabatini AG (2007) Chemical characteristics of poplar type propolis of different geographic origin. Apidologie 38:306-311

28. Pearl IA, Darling SF (1971) Studies of the hot water extractives of the bark and leaves of Populus deltoides bart. Can J Chem 49:49 55

29. Devappa RK, Rakshit SK, Dekker RFH (2015) Potential of poplar bark phytochemicals as value-added Co-products from the wood and cellulosic bioethanol industry. BioEnergy Res 8:1235-1251

30. Zhang XF, Hung TM, Phuong PT, Ngoc TM, Min B-S, Song K-S, Seong YH, Bae KH (2006) Anti-inflammatory activity of flavonoids from Populus davidiana. Arch Pharm Res 29:1102-1108

31. Baiocchi C, Marengo E, Roggero MA, Giacosa D, Vietto L, Toccori S (1994) A chromatographic and chemometric study of the bark phenolic compounds of two poplar clones with different resistance to Discosporium populeum. Chromatogrph 39(7/8):481489

32. Todaro L, Russo D, Cetera P, Milella L (2017) Effects of thermovacuum treatment on secondary metabolite content and antioxidant activity of poplar (Populus nigra L.) wood extracts. Ind Crop Prod 109:984-390

33. Gähler K (2015) Untersuchungen zu systematischen und zufälligen Fehlern der nasschemischen Methoden zur Bestimmung der Pflanzenbestandteile Cellulose, Hemicellulose, Lignin sowie Extraktstoffe. Master Thesis, TU Dresden

34. Amborabé B-E, Fleurat-Lessard P, Chollet J-F, Roblin G (2002) Antifungal effects of salicylic acid and other benzoic acid derivatives towards Eutypa lata: structure-activity relationship. Plant Physiol Biochem 40(12):1051-1060

35. Vio-Michaelis S, Apablaza-Hidalgo G, Gómez M, Peña-Vera R, Montenegro G (2012) Antifungal activity of three Chilean plant extracts on Botrytis cinerea. Bot Sci 90(2):179-183

36. Steanovic T, Diouf PN, Garcia-Perez ME (2009) Bioactive polyphenols from healthy diets and forest biomass. Curr Nutr Food Sci 5:264-295

37. Walters D, Raynor L, Mitchell A, Walker R, Walker K (2004) Antifungal activities of four fatty acids against plant pathogenic fungi. Mycopathologia 157:87-90

38. Kaur R, Kaushal S, Sharma P (2018) Antimicrobial and antioxidant potential of pomegranate (Punica granatum L.) peel. Int J Chem Stud 6(5):3441-3449

39. Einer D, Bremer M, Oktaee J, Fischer S, Wagenführ A (2019) Identification of fungicidal components in poplar bark from short rotation plantations. Holztechnologie 60:5-17

Publisher's note Springer Nature remains neutral with regard to jurisdictional claims in published maps and institutional affiliations. 